\title{
Thinking with Digital Images in the Post-Truth Era: A Method in Critical Media Literacy
}

\author{
Nataša Lacković ${ }^{1}$ (D) \\ Published online: 5 February 2020 \\ (C) The Author(s) 2020
}

\begin{abstract}
This article introduces a new method to support critical media literacy, learning and research in higher education. It acts as a response to an unprecedented profusion of visual information across digital media that contributes to the contemporary post-truth era, marked by fake news and uncritical consumption of the media. Whereas much has been written about the reasons behind and the character of the post-truth, less space has been dedicated to how educators could counteract the uncritical consumption of images from the perspective of semiotics. This article adopts a unique semiotic approach to address the stated gap. It discusses in depth the meaning making of pictures, digital photographs and material objects that photographs can embody. It does so by focusing on three aspects of a pictorial sign: (1) the materiality of its representation and representational elements, (2) its object (what the sign refers to) and (3) its descriptive interpretations. These three aspects inform the signification analysis within the proposed productionsignification-consumption (PSC) method, exemplified with digital photographs. Understanding and analysing images via the PSC method draw attention to how humans create, interpret, (re)use, consume and respond to online and offline communication signs. The method can contribute to the development of critical media literacy as an engagement with postdigital semiotics, much needed in an age of global ecological and social crises, uncertainty and fast consumption of digital content.
\end{abstract}

Keywords Photographs · Method · Analysis · Postdigital semiotics · Critical media literacy

Nataša Lacković

n.lackovic@lancaster.ac.uk

1 Lancaster University, County South, Bailrigg, Lancaster LA1 4YL, UK 


\section{Introduction}

I've been looking so long at these pictures of you

That I almost believe that they're real

I've been living so long with my pictures of you

That I almost believe that the pictures are

All I can feel.

The Cure, Pictures of You (1989)

Pictorial signs such as photographs act as captivating, persuasive and affective artefacts that attach the viewers to the beings and things that they embody. Such an intimate relationship between individuals and pictures has been translated and appropriated into the post-truth relationship between the public and the media. This article uses the post-truth condition and digital media image saturation as a trigger to discuss the importance of interpretation in human understanding of the world. The article introduces an educational method to support an inquiry of digital photographs. It offers a novel analytical framework that can be implemented in the curriculum and research. This is needed to address the current state of human-media interaction, as we live in a world 'of hyper-visuality, in a world of remediation and cross-mediation in which experience of content both appears in multiple forms and migrates from one form to another' (Bolter 2001; Peters, Besley, Jandrić and Bajić 2016: 2). Such hyper-visuality operates in a postdigital bubble where promoted media content seamlessly infiltrates and influences online and offline behaviours (Besley et al., 2018). It stirs media users to seek instant, affective and comforting solutions to difficult and complex problems, tapping into the public fear of insecurity, conflicts and uncertainty. In such a society of spectacle (Debord 1994), higher education across disciplines would benefit from a serious analysis of visual media meaning making (signification) that foregrounds the role of human interpretation, affect and subsequent action in education and society.

The persuasive and aesthetic power of pictures has been discussed and exemplified in a variety of fields over decades, such as visual culture, visual persuasion, media studies or art history (e.g. Mirzoeff 2002; Mitchell 2013; Mitchell 2005; Smith 2008; Bal and Bryson 1991; Sontag 1997; Panofsky 2018). The affective and signifying value of digital pictures has contributed to the thriving of the ambiguous post-truth space in between truth and lie, reason and instinct (Jandrić 2018). However, it is not that the so-called post-truth era promotes less truth than any previous time in history. The scale of visual media presence and outreach has furnished the strange liminal space where lies can thrive and spread to an extent previously unimaginable (Peters, Rider, Hyvönen and Besley 2018). The massive scope and visibility of truth and fact rejection in the media are overwhelming and disturbing.

Much has been written about the post-truth in relation to social media, world politicians and various organizations; the relation between the post-truth, knowledge and education has been theorized from a critical theory and pedagogy perspective (e.g. Ford 2018). This article does not aim to analyse or theorize the post-truth era per se or delve into nuances of lies and fake news associated with it (see MacKenzie and Bhatt $2020 \mathrm{a}, \mathrm{b})$. It discusses the truth and digital photographs' connection to abstract and concrete concepts from a semiotic perspective. It tackles the nuances of how digital photographs signify and mediate human interpretation and action, to take pictures in higher education seriously as both information and learning resources. In that way, it contributes to the remedial activity towards the picture-saturated post-truth condition. 
To do so, it develops Charles Sanders Peirce's schematic tripartite sign into an analytical model. Although media literacy and semiotics have been linked and explored before (Gaines 2006, 2010), analytical applications of Peirce's triadic sign are scarce in the field of critical media literacy. As Bulger and Davison (2018) argue, media literacy 'has become a center of gravity for countering "fake news"'. The proposed analytical method can challenge the society as a consumerist market place of everything (Hayes 2019), wherein relentless consumerism based on individualism and affect flourishes in an accelerated society with little time for in-depth reflection and inquiry.

Questioning the 'truth' value of pictures has had a long tradition. Nöth (2002) proposes that semiotics can provide tools for analysing the truth or lies in pictures without a logocentric bias. Nöth reflects that pictures have been scapegoats for those who 'foresee an apocalypse in the domain of media studies' (2002: 133). The author argues that this is a long-standing bias, referring to Gustave Le Bon, who, in his work Psychology of the Masses, 'accuses' the picture of their lowly character to serve the deception and manipulation of the (quote) 'primitive ones' (Le Bon 1895 in Nöth 2002: 133). Nöth criticizes Le Bon referring to his words: 'The masses can only think in images and can only be influenced by means of pictures. Only pictures can frighten and persuade them and become the causes of their action (...) To them, the unreal is almost as important as the real. (LeBon, 1895, \&3.2)' (Nöth 2002: 133).

Associating pictures only with mass thinking and media persuasion, as equal to some 'primitive' way of thinking, is highly problematic. It has contributed to undermining pictures in education. Arnheim (1997) argues that perception is not isolated from thinking and that visual and other types of sensing are prerequisites for and a part of thought and cognition, and not lower level signs in communication. Although perception and corporeal sensing are not the same as knowledge, they are a part of knowledge. Photographs can act as thinking tools, as semiotic scaffoldings and semiotic bridges between abstract concepts and the physical world in an educational inquiry. The point is not to separate the visual and material world from reasoning and learning (Arnheim 1997), and not to separate reasoning and learning from interpretation in higher education practices.

Despite the proliferation of visual media in students' lives, higher education programmes or subjects across disciplines do not consider photographs as learning or analytical resources, apart from those traditionally understood as 'visual' or imagefriendly. There are practical and systemic obstacles for greater pursuit of multimodal and visual practices in higher education. However, this needs to be tackled (see Gourlay 2010). In the 1980s, Sless (1981) was referring to what could be called a type of academic iconophobia (fear of images). He was referring to the failure at universities to engage with images and their role in the curriculum across disciplines. This situation still prevails. In a world where a vast number of learners engage with overwhelming pictorial content daily, a turn to examining and understanding digital communication mediated by pictures can be beneficial for contemporary higher education.

\section{A Semiotic View on Communication: Digital and Visual Sign, Interpretation, Truth and Affect}

If digital communication is at the core of present-day communication and education, what is the key unit of digital communication? Peirce's semiotics offers an 
encompassing answer that includes language and narrative but does not adopt a logocentric approach for all media and modalities, such as images. Semiotics is the study or the theory of signs and how signs make meaning and mediate acting in the world. The key unit of digital communication and digital semiotics is a digital sign. Digital semiotics tackles studying, analysing, conceptualizing, theorizing, producing and using digital signs across domains of educational and everyday life. Simply put, a digital sign is anything that makes meaning used in digital communication. A digital sign is explored in this paper mainly via digital photographs, as a relational, tripartite entity of the sign's embodied digital form (a version of Peirce's representamen), what the sign form refers to (its object) and its interpretation (interpretant) (see Fig. 1 that illustrates this relational triadic structure of a photographic sign). A postdigital sign is a sign that can and does appear both in virtual and physical world environments, acting as a communication and meaning-making mediator in both, blurring the boundaries between them. Therefore, the study of postdigital signs can be named postdigital semiotics, characterized by studying the meanings and effects of signs in online and offline environments and their relationships with sociocultural and ecological change (e.g. changes in structure, agency, being, action). Digital photographs, hybrid signs such as memes, linguistic text and narratives, numbers, gestures, digital devices' portability, uses and functions, gaze and architectural, material and industrial design particularities can all act as postdigital signs, and they can be subjected to inquiry.

One of Peirce's definitions of a sign is: 'A sign, or representamen, is something which stands to somebody for something in some respect or capacity' (CP 2.228). In this definition, Peirce draws a clear parallel between a sign and representamen. Peirce's own definitions of the sign and representamen have varied over time (see Benedict 1985 and Nöth 2011). The representamen in the present work focuses on the materially visible, identifiable and describable content of a photographic representation, adapting Peirce's definition of representamen as 'the concrete subject that represents' (CP

\section{Interpretant (Photographic meaning)}

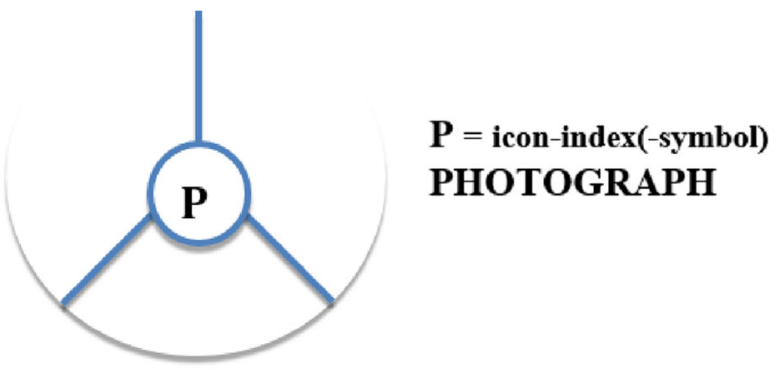

Representamen

Object

(Photo existence; photo form) (What the photo resembles)

Fig. 1 How a photographic sign makes meaning, building on C.S. Peirce's sign diagram (Merrell 2005). Legend: representamen $=$ a photograph's embodied form/sign's embodiment, interpretant $=$ meaning $(\mathrm{s})$ made by interpreters and object $=$ what the photograph's pictorial form stands for in the world 
1.540). My interpretation relates to Elleström's (2014) interpretation of representamen for the study of media and arts, focusing on materiality as an aspect of representamen. It also relates to Peirce's definition of iconic sign as 'any material image, (such) as a painting (ms, 478, p.45-6)', quoted by Freadman (2001). As such, it could be also proposed that the representamen version adopted here is to some extent closest to semiotic terms tokens and replica (Parker 1998), as '(a) replica is the vehicle of the sign. It is composed of ink, sound waves, or some physical stuff' (Nöth 2011: 456; Parker 1998: 153). I focus on the quality of a digital photograph to represent its object by embodying it on the screen. I acknowledge that this is a specific interpretation of representamen. Perhaps the term to be used here for representamen is sign's embodiment, as suggested by Nöth (2011: 461). I continue the discussion in the article with reference to such an embodied, photographic representamen.

Applied to digital photographs, Peirce's triadic sign (Fig. 1) can help understand the difference between the signs' object (itself) and the form representing that object, the digitally embodied representamen. These three sign nodes (object-representameninterpretant) always happen simultaneously when meaning is made, for example, by a human being. They are interpretative, inseparable, emerging and relational. A photograph acts as a compound sign in digital communication, an icon-index-symbol sign. A photograph is iconic, because it signifies according to the similarity (near-toisomorphic resemblance) between its object and its embodied representational form (representamen). Such type of signification by similarity is a characteristic of an iconic sign. In addition, a photograph is also an indexical sign, as it signals the existence of the object it shows (CP 4.447), a kind of physical and existential relation to it. Peirce mentions a photograph as an example of an index via its optical connection with the object (CP 4.447). If there is a photograph, there exists a physical object that it represents, unless the photographic representation is fabricated in some way, and this can happen. Furthermore, when entering and supporting communication purposes, a photograph acts as a symbol, to signify a meaning conventionally assigned to it, a habituated idea or concept. A symbolic photograph that plays with collective desire (e.g. by constant repetition and reuse in the media) is what Barthes (2009/1972) calls a myth, such as a photograph of some woman being a symbol for femininity. This view of a compound communication sign also echoes Nöth's (2011: 461) reference to Santaella Braga (2003: 51), who posits that 'without its indexical ingredient, the symbol would have no power of reference, and without its iconic ingredient it would have no power to signify'.

To exemplify photographic sign's embodiment and meaning making, photographs are often used in the media as digital embodiments of abstract concepts. The concept of climate change can be embodied via a variety of photographs that can stand to represent something about the climate change. An abstract concept is imagined by humans via linking it to its concrete manifestations (Tateo 2018), for example, via photographs. The photograph itself represents something concrete that has happened or can happen in the world. In the case of the present concept example (climate change), this can be the polar ice melting and the movement of icebergs. However, the embodied representation is not the concept itself. Via the representational quality of its medium, a photograph of an iceberg shows an actual iceberg existing in the world and evokes a general concept of an iceberg as its object. If this photograph is used to represent the concepts of climate change or global warming, then it has an assigned conceptual object, used to illustrate an 
existing or possible manifestation of that concept. The conceptual (symbolic) object is superimposed over the embodied iconic object, turning the photograph into a symbolic representation of the concept. In other words, when a viewer sees a photograph of melting polar ice, the viewer can adopt the interpretation of this embodied representamen as a symbol of the climate change or global warming or something else, accompanied by an affective reaction linked to it, such as anger, indifference or sadness.

Concepts such as icebergs, rivers, water, soil, oil, trousers and houses are all concrete concepts that exist in our sensed physical reality. However, a vast number of concepts, perhaps most concepts that humans use in communication and place affective and ontological importance on, are abstract concepts. These are the concepts such as love, happiness, security, belonging, democracy and economy. In society, we learn to imagine and conceptualize abstract concepts, building on our personal, environmental and educational background, as well as our corporeal and affective experiences (Tateo 2018). Educators need to support learners to engage with these interpretative nuances and explore how images, abstract or concrete concepts, symbolic meanings and truth are consistently linked in life, education and the media.

According to Peirce's semiotics, as humans, we always interpret what we see; hence, we cannot know an absolute truth of the sign or anything observed and sensed, although there are real and true things. It is so because 'our knowledge is never absolute, but always swims, as it were, in a continuum of uncertainty and of indeterminacy' (Almeder 1980: 47). This is important for tackling the meaning of any sign in communication. By understanding the primacy and limitation of our interpretative faculties and their intrinsic connection to corporeality through affect and other physical sensations (Tateo 2018), we can acknowledge corporeality/embodiment of interpretation. We can focus on the inquiry of a sign in as many details as is possible, to cultivate critical semiotic awareness. By claiming that all human knowledge is fallible, Peirce does not reject the pursuit of truth as scientific fact and the goal (Almeder 1980). Rather, he stresses the continuity of knowledge and consistent growth thereof via signs, emphasizing the constant evolution and indeterminacy of meaning that happen in our world, what he calls synechism (Almeder 1980: 47). What is possible (albeit still difficult) for humans is to reach an agreed opinion about the sign and provide a factual statement about the sign. This would be preferably reached by most diverse research and scientific communities in one field and across disciplines, including public inputs. If there are two competing interpretations of and approaches to one thing, it means to ask why it is so and what can be done to reach an informed conclusion.

Interpretations of contemporary signs, such as the ones circulated on digital media, are mainly anthropocentric, made by and about humans. They often disregard the presence and layered meanings of the visible and invisible forms of the world and life. A photograph shared in the media commonly shows some material things captured in the world. By representing things existing in the world, digital photographs, accompanied by media captions or texts and on their own, can suggest meanings about those things represented and suggest action in relation to them (to interpreters). An embodied representamen of a photograph can provide one of many possible concrete manifestations of an abstract concept, as exemplified above, which can be interpreted differently by different interpreters. Even concrete concepts that embody physical aspects of the world (e.g. house) do not have singular meanings. 
If I am in front of a house, the existence of that house at that moment in the world is real and true. As an object made of hard material with specific compositional characteristics, it has an existential material form. I can treat a house as a sign that I can use in communication. The definition of house as a concrete concept represents an agreement among assigned scientific and linguistic communities on what the most general and supposedly most widely accepted meaning of house is to call it a house. The English Oxford dictionary says that it is 'a building for human habitation' (a part of the definition), but we know very well that different organisms can and do dwell in houses: pets, plants, tiny animals like spiders and ants, mould, different forms of matter, invisible things such as microbes and so on. We also know that house is connected to many affective and aesthetic meanings assigned to it. When considering an emotional attachment to the house, the house becomes a home. Whether it has high ceilings or low ceilings, white or red walls, makes a difference in terms of how it feels. Therefore, by being embedded in the complex socio-material world (Fenwick, Edwards and Sawchuk, 2015), the house is much more than the existential realness of its matter or its dictionary definition. Educators need to encourage learners to explore the complexities and plurality of concepts and visual signs that embody them.

What humans can grasp and define is very much like truth, but not the very truth itself: '...we are so far from ever being authorised to conclude that a theory is the very truth itself $(. .$.$) we can never know precisely what we mean by any description$ whatever' (Almeder 1980: 47). That is why theories and concepts are interpreted differently by different people, depending on the context, prior knowledge and many other factors. Merrell (2005: 28) emphasizes the point made above how reality is only 'semiotically real', as absolute knowledge is impossible:

I will allude to Peirce's object as the 'semiotic object', for it is that to which the sign relates. The semiotic object can never be identical to the 'real' object (...). Our knowledge can be no more than an approximation to the 'real' world exactly as it is, or better, is becoming.

Therefore, the 'real object' 'can never be more than "semiotically real" for its interpreters' (Merrell 2005: 28). The above-stated fragility of knowing the truth of any object and the true object of a pictorial sign can be exemplified as a possible theme of The Treachery of Images (Fig. 2, the painting by famous Belgian artist René Magritte. The artist produced a plethora of paintings that blurred the boundary between words and images, real and imaginary and concept and picture. In The Treachery of Images, the painter created a clear lined, simple realistic image of a pipe, centrally placed on the canvas, with the legend beneath it proclaiming C'eci n'est pas une pipe (This is not a pipe). The painting itself is probably an overused reference, but it might be familiar to the widest readership.

This is a good example of how meaning making works as we could say that the relationship between the material representamen and its object is openly disturbed, and our certainty of knowing the object gets openly challenged. A drawn pipe resembles something, an object that we call a pipe. The painting is not a pipe though, as it is a representation of a pipe. The viewer knows this analogy, but the label in the painting might have been intended to shake our knowledge of things. Evans (2005) provides the following interpretation: 


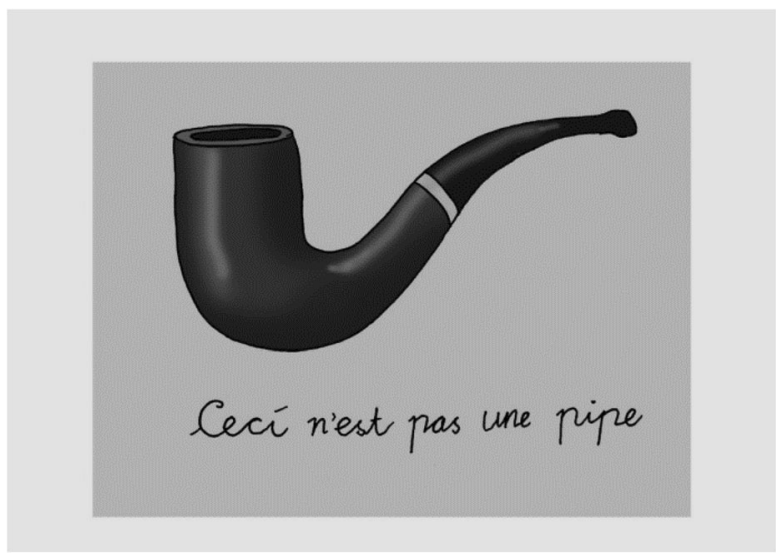

Fig. 2 A drawing of Magritte's painting The Treachery of Images (La Trahison des images). Courtesy of Andi Setiawan, (C) 2019 Andi Setiawan, all rights reserved

the 'anchor' of resemblance, the object being depicted, hasn't in fact disappeared (as Foucault would have $\mathrm{it}^{1}$ ) from Magritte's drawing but that instead Magritte has used this 'anchor' to remind us just how limited our ability to apprehend the object actually is. Namely, that our categorization of a really existing object with such and such physical qualities is based on habit, custom, and experience, and not because the object is the actual essence we give it (i.e., this object we call a pipe, because it was built in the manner that it was, facilitates the act of smoking but can never be wholly defined as being that and only that).

The viewers could feel caught 'hanging' - 'stripped of both the depicted object's human-given essence and the possibility of defining an objective existence for it - thus forcing us to confront the ambiguity of existence' (Evans 2005). This further illustrates the arguments of not being able to know the absolute truth, as it is unreachable to humans. It is not to claim that this interpretation of the painting is the only one, of course not. It emphasizes the fluid, unsettled relation between what we see and what we know (Berger et al. 1972).

In education, we do need to have some operational definition of concepts that we encourage students to learn. This is useful and necessary. However, we also need to support students in understanding the complexity, heterogeneity and evolutionary character of meaning making and learning, especially with regard to culture (Olteanu 2019). By observing and sensing, we are inherently a part of the environment and its system of things and beings, and we learn meanings embedded in our interactions in and with the environment. The environment and any entity in it influence each other. Semiotics can help describe the structure of the world and how this structure links to human action, affect and, in general, the world's animate and inanimate matter and sociocultural exchange of meanings. Postdigital semiotics can study online-offline environments and socio-material relations and change concerning postdigital signs. We could possibly view all signs as postdigital, if they can be embodied in or mediated by digital devices. Photographs are specially

\footnotetext{
${ }^{1}$ In his essay 'This is not a pipe'
} 
interesting as they are supposed to represent a palpable, believable physical reality, but in their digital form, this representation becomes a digital code of pixels, suspectable to modification and online sharing at any moment. If meanings are constantly assigned to the observed or sensed, an analytical method that explores nuances of how meanings are assigned and with what effects is a worthwhile engagement in education to support communities of inquiry.

\section{Production-Signification-Consumption (PSC) Method and Analysis}

As Peters (2017: 565) observes in relation to education and post-truth, '(c)riticality has been avoided or limited within education and substituted by narrow conceptions of standards, and state-mandated instrumental and utilitarian pedagogies'. In order to cultivate a more critical and deeper appraisal of images and their role in innovative and progressive pedagogy and research, this article proceeds to build on the discussion so far. This section introduces a novel media and postdigital inquiry method, a production-signification-consumption (PSC) method. The method builds on the premise of the three sites of image meaning making developed in visual research methods: (1) production, (2) consumption and (3) the image itself (Rose 2006).

\section{Production-Consumption Site, Intentionality and Image Digital Life}

When tackling pictorial meaning in visual research methods, Rose (2006) talks about three sites of image meaning making that are important to be considered in picture interpretation and its effects in the society: the image production, the image itself (e.g. its materiality and composition) and the site of image audience who consume images. The PSC method builds on this aspect of visual research methods (Rose 2006). In terms of digital image production and reuse, human intent is important in defining the meaning and intentions 'behind' image uses. Some key questions aligned with image production and consumption inquiry as well as affect are here exemplified with the focus on photographs:

Photo-production critical questions:

- Where does the photograph come from? Who is the source of information?

- Can its origin be defined (could possibly be traced via Google Image 'Search by image' function (the photo camera icon))?

- Who created it, why that author/organization/group?

- Where was the photograph taken?

- When was the photograph taken (era/decade/year)?

- Why was it created and with what purpose?

- Does it look staged; is it a stock photo?

Photo-production affect questions:

- Is there an affective intention behind its production; what could it be (what are the intended desires and values of the consumers/audiences that are targeted by the producer(s))? 
Photo-consumption and reproduction critical questions:

- Who consumes the photograph? Who are the photograph's intended consumers/ audiences (this links to production)?

- Is the site of the photograph consumption the same as the site of the primary photograph appearance, provided by the author and creator? How can we know this (Google 'Search by image' could provide some clues)?

- What is the photograph's digital life? How is it repurposed and reused on the Web, to serve what purposes? Does it appear everywhere in the same form or it is modified (e.g. into a hybrid sign such as meme)? Where (what digital platforms and media) has it been uploaded on (use Google 'Search by image')?

- What words are used with it, what labels and descriptions? Are they similar or different, how do they aim to define the photograph, and with what effects on viewers-consumers?

Photo-consumption affect questions:

- What are (can be) the affective reactions to the photograph consumption by various audiences? Why? Was this reaction intended by the person creating and/or the person uploading the photograph?

- Could a dominant reaction be identified in particular groups and across groups and why? Is there any evidence of how viewers react to the photograph?

- What are/could be the differences in reactions by different viewers, and why?

In today's postdigital landscape of photographic upload frenzy, it can be hard to trace the digital life, birth and reauthoring of photographs, as they are readily appropriated, repurposed, modified, collaged and/or labelled with new texts. Even if some questions above are hard to answer, considering them supports critical reflection and acknowledges that complex factors contribute to visual media meaning making, but they are not transparent and readily available to the public. In the frantic digital production and dissemination medley, the visual has become a part of a power game and media wars, where careful orchestrations of film, television and advertisement production go around in global circles (Mirzoeff 2002).

\section{Signification Site of the Image Itself Via Focused Inquiry Graphics Analysis}

The signification aspect of the PSC embeds an inquiry graphics (IG) analysis (Lacković 2018), as it is aligned with Peirce's tripartite sign explained above. Each of the triadic nodes (representamen-object-interpretant) focuses the analysis and inquiry on the sign as follows: the embodied representamen focuses the analysis on researcher's, learners' or participants' observing, naming (as singular nouns) and listing of the embodied content of the photograph; the interpretant-led analytical step focuses analytical attention on the researcher's, learners' or participants' interpretations; and the object of inquiry (conceptual object, research object) step focuses attention on the symbolic meanings linked to theory, research questions or pedagogic goal. Such an inquiry of the relations between graphic embodied representamen, its symbolic object and interpretations concerning a theory or concept is a central tenant of turning any graphic sign 
such as digital photographs into inquiry graphics. For example, an inquiry graphic activity would encourage learners or research participants to find or make photographs that can represent an aspect of an abstract concept, such as the broad concepts of democracy or social (in)justice or more specific concepts of constructivist learning in Educational Psychology. The steps of inquiry graphics are explained below as: (1) digital materiality and photo content naming (embodied representamen), (2) descriptive interpretations (interpretant) as denotation and connotation descriptions and (3) object of inquiry (conceptual/research/thematic object, what the photograph refers to in conceptual and theoretical inquiry terms).

\section{Digital Materiality and Photo Content Naming (Embodied Representamen)}

In terms of the pixelated truth of digital photographs, this means to define the highest or nearest level of isomorphism of a photograph's digitally embodied representamen to its object (Nöth 2002). The nearest-to-truth representamen is the one that corresponds to what it depicts factually, that is, a point-by-point representation of what it shows (its object) (Nöth 2002). It means that no aspect of its projected point-by-point form has been modified within and just after the first photographic processing. We are all aware that photographs can be modified, filtered and enhanced. To decide whether a photograph promotes a lie or not by considering photo-users (producer/uploader/consumer), intention is important. However, this is a different consideration from considering the level of representational pixels near-isomorphism of the photograph itself.

By knowing that a digital camera modifies picture representation to however minute extent (image filters), the camera user makes a conscious choice that such a minute modification is acceptable. In a culture where digital modifications have become widely accepted and 'seamless', the distinction between actual reality and idealized reality is increasingly blurred, and every mobile camera filter user contributes to that, whether they have an intention to deceive or not. Issues can then arise when such minute modification becomes naturalized, to give way to another one, and another one, until the idealized is so normalized that it becomes the norm and an ideal 'truth'. I am not talking here about specific uses of digital images such as digital art, games or scientific illustration purposes, as these merit another article, but daily uses of common photographs in social and news media. Again, it is hard to make conclusions about both photograph modification and producers' intentions, considering today's circulation of photographs and hybrid visual media, but these need to be considered and, importantly, discussed among learners and educators. It is worth contemplating that each photograph circulated in the media is potentially modified (e.g. the under-eye circles are casually airbrushed on the faces of women on magazine covers). Certainly, having a clear deceptive intention with an image is an offence at a completely different scale, compared to casual, personal and entertainment uses of digital and phone cameras. However, these subtle uses of images might have become and are becoming so seamless that they are contributing to a slow but steady change of our perception and sense of self and our surroundings. These kinds of changes are exactly what postdigital semiotics can help explore. 
The article will now proceed to focus on the content of photographic representamen as a postdigital sign for the purpose of analysis. Imagine a photograph showing a person, let us say someone who looks like a man (could be of a different gender) being physically assaulted by some hands pulling this man from the back, and his face and facial expression are visible. An analysis of the photograph itself would start with identifying, naming and listing all individual elements shown in the photographic content (this is $\mathrm{R}=$ representamen-led interpretation). Elements are listed as singular nouns (a man, a jumper, a hand, a pavement and so on). Nouns as elements are used to state that something is present in the photograph. Considering details in photographs focuses the attention on how all the individual elements shown all equally contribute to the overall meaning making and can serve as springboards for creative and critical insights. Elements can be listed with regard to the elements' positioning and to the space occupied (from larger to smaller spatial characteristics, e.g.: a man, a body, a face, an eye, a pupil and so on). Element naming can involve interpretative category variations (e.g. shoes or a shoe type such as sneakers or sandals). Element naming is an interpretative analytical step, just as all sides of the triadic relation are interpretative. Even more sense-nuanced aspects of representamen such as colour and shapes can also be the starting point of representamen-led naming and listing. The point is to first focus on the art of perceiving (Arnheim 1997). An example question for this step in the analysis would be:

- Can you name, list and number everything you see, from bigger to smaller individual items (things or elements) represented (to the extent that can serve your analysis goals)? For a fine-grained analysis, note the smaller things that are a part of larger things (e.g. eyes-head-body, graphite-pencil, handle-mug and so on).

- Do you think that this photograph has been modified in any way, and if yes, what might have been modified?

\section{Descriptive Interpretations (Interpretant): Denotation and Connotation}

Interpretant (I) analytical focus proceeds to describe the photograph in two distinct steps. These distinct steps build on Barthes' (1988) semiotic distinction of denotation and connotation. A denotation level description of the photograph, adapted from Barthes (1988), would go on to describe the stated photographic elements: what they look like or do and what is happening to them (e.g. for the element 'eye': 'the eyes look (seem) wide open'; 'the man is wearing shoes; the shoes look worn out or brown'). These descriptions would take the form of 'simple' descriptions, with the frequent use of speculative verbs such as 'seems', 'looks like' and 'is possibly' with descriptive adjectives or adverbs. The use of speculative verbs as an open-ended description stresses that something one person sees and describes might not be the same as what someone else sees or might not be what it seems to be to the interpreter; hence, the heterogeneity of meanings is practiced. The denotative descriptions can be compared across interpreters to see what occurs in all learners' (or research participants') interpretations, if anything, and where the main differences arise or what is omitted.

Some of the key questions for this analytical step would be: 
- Can you describe what is happening in the photograph, by using words and constructs that signal individual interpretation such as 'it looks like', 'it seems to me' and 'it is possibly'? This description is a simple level description that involves speculative verbs (seems, looks like), descriptive adjectives of states (open, closed, red, muddy, dry, small, etc.) and adverbs to denote what things or phenomena represented look like to individual interpreters at a basic level of interpretation.

- What is not shown in the photograph, but it could have been? Do you feel that something is omitted/missing from the photograph, but it could be there?

The interpretation would then move on to connotation adapted from Barthes (1996), which is where the interpretative diversity starts to become more distinct. Further sociocultural meanings of denotative descriptions are assigned to the photograph by interpreters, e.g. when the denotatively described expression in the man's wide-open eyes is interpreted as 'victim's discomfort and fear (the man in the photo becomes a victim as the roles of victims and perpetrators, powerful and powerless are socioculturally assigned meanings to the described acts)'. At this stage, it is important to stress that various interpreters would have different interpretations of what sociocultural meaning is shown, determined by their background, prior knowledge, upbringing and experiences. The exploration of these connotative meanings can include these questions:

- What do you think the sociocultural meaning(s) of the description is?

- How do you know its cultural/social/national context?

- What could the gazes (e.g. direct, away, upwards, downwards), body positioning and interaction of the people be suggesting, and what effects these can have on viewers?

- What about the roles of the observed people, and what function would material things have (e.g. an observed woman could adopt a role of a student, teacher, manager, mother, housewife, scientist and prisoner; a heavy book can be a learning, art or assault object and so on)?

- Why? Why do you interpret the look of this image or its element(s) to mean what you assign to it? What informs you? How have your social and cultural experiences informed the meanings assigned to this image?

- How can we estimate the era/decade/year when it was taken?

- What could have happened before and after the photograph was taken?

- What are the possible alternative interpretations of the sociocultural meanings that were possibly intended and interpreted by you?

- How would meanings change dependent on different viewers/context/place/time of consumption (e.g. if the photograph relates to your sociocultural context, would a similar photograph exist in your context, in what ways and what informs your claims? If it does relate to your context, how would it exist or be presented in other contexts?)

- How have the represented things and their meanings changed historically, over time?

- How do the interpretations you assign to this photograph make you feel?

These discussions would illuminate human embeddedness in the society and socially constructed meanings, as well as human vulnerability to accepting or seeking a truth in 
media information that most appeal to their prior knowledge, experiences and desires (Arnheim 1997), including the human need for certainty and stability in life, defined by class, economic, educational and demographic background. A digital photographic image is powerful in shaping the value attached to the external world, which can be used to enhance the packaging of the truths promoted in the public media. Photographic and pictorial connotations reinforced in the media have become so symbolically commercialized and status and success driven that they act as ideological signs, a Barthesian myth (Barthes 2009/1972). This also signals the political and ideological meaning of visual signs, for example, via the politics of pictures selected to be promoted in the news media, in education and in international curricula (Lacković 2010a).

It is important to be careful what can be claimed about an image in an image description, as suggestions need to be derived from careful act of perceiving and reflecting of what the image shows and what it does not show. For example, no photograph shows fear via its representational quality (digitally embodied representamen), but humans interpret it as such. That is why it is recommendable to use probabilistic verbs or at least signal this when interpreting. A photograph shows a material form, e.g. it could be a facial expression and action that we interpret as 'fear' or related to fear. This means that in a learning community, a teacher can ask students to explore these nuances of meanings and sociocultural practices. In the post-truth times, learners could, for example, find and analyse images on the same concept or topic on various websites or social media accounts that offer contradictory representations and interpretations.

\section{Object of Inquiry: What the Photograph Refers to in Conceptual and Theoretical Inquiry Terms}

In the final analytical stages of signification, the inquiry would tease out possible links between the image and the focal concept, theme or question in the inquiry. This educational concept is analytical (conceptual and research) object or the superimposed object of inquiry. It can be a concept assigned to an image, a theme, its claim to truth, a label given to the image or any statements in the media attached to it (perhaps in the news). The questions that will unpack the conceptual object of inquiry can be as follows:

- How are individual image elements of embodied representamen and interpretant descriptions linked to the concept/theme/the chosen theory of inquiry or any truth claimed or statements about the photograph made?

- What theoretical or conceptual knowledge can help illuminate the meanings and effects of the sign?

- How can the characteristics of the listed individual elements and interpretant descriptions bring in new ideas and insights about the concept explored or the claims that the image is supposed to offer (e.g. via caption or text)?

- Can I probe this concept further, stretch it and challenge it?

Teachers rarely encounter such approaches when preparing to teach. Inquiry graphics can help teachers go beyond assimilating visual media at the level of an illustrative role towards integrating those at a deeper learning level into subjects' inquiry (Lacković, 
Crook, Cobb, Shalloe and D'Cruz 2015). The power and uniqueness of an inquiry graphics analysis are in creating this exploratory space in between a picture and idea, a possibility and actuality (Bruner 2009), for tackling sociocultural interpretation seriously. It is a space for considering possibilities for meanings at the intersection of the conceptual and the material, including previously unimaginable or unconsidered possibilities and solutions.

The proposed Peircean approach acknowledges the heterogeneity of signassigned meanings. This suggests that conclusions about a concept or problem or statement need to be consolidated from interpreters who usually represent opposites in terms of their views or experiences but are equally positioned as experts, producers and users in a field of inquiry. That is why more international and collaborative programmes in HE could provide potent opportunities for such inquiry and research. This also means that, for example, the reports of any national, Western, Eastern or any media would need to be questioned by learners and viewers if they highlight only one point of view (and commonly they do so). An inquiry graphics analysis usefully highlights the plurality of meanings via a systematic analytical approach, without succumbing to the relativization of truth. The complex inquiry graphics sign with superimposed inquiry object is presented diagrammatically in Fig. 3 and accompanied legend below.

\section{I (PI-CI) - CCI}

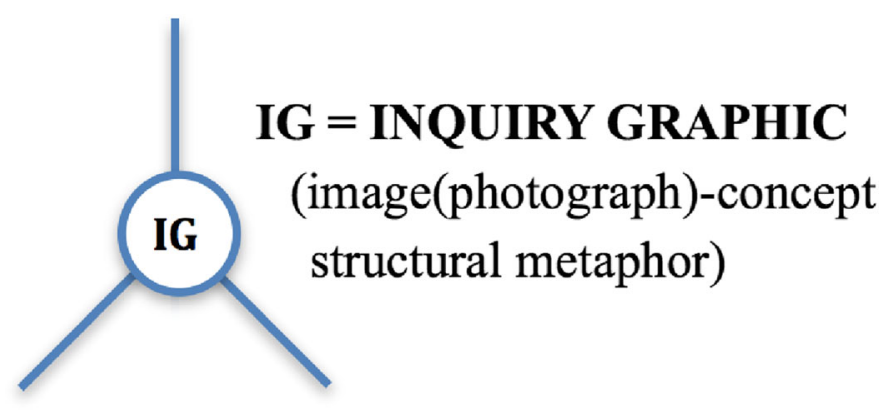

\section{$\mathbf{R}$}

\section{O (PO-CO)}

Fig. 3 An inquiry graphic's schematic diagram building on Peirce's triadic sign. Legend (here exemplified for photographs, but applies for other pictorial signs): $\mathbf{R}=$ embodied representamen: the embodied and descriptive photographic existence and form; analytically it involves listing observed elements as singular nouns, single things observed; $\mathbf{I}=$ interpretant (interpretation by students, research participants); PI = pictorial element interpretation; $\mathbf{C I}=$ concept/theme/disciplinary domain of inquiry interpretation concerning $\mathbf{C O}$; PI consists of photo denotation, basic description - 'noun' + 'looks like/seems to be' + adjective and/or adverb - and photo connotation. Further interpretation of contextual sociocultural meaning of denotation; $\mathbf{O}=\operatorname{object}(\mathbf{P O}=$ pictorial object: what the photograph's embodied representamen stands for; $\mathbf{C O}=$ conceptual object $=$ the concept/theme assigned upon/superimposed over the photograph, commonly an abstract concept); $\mathbf{C C I}=$ critical concept inquiry: IG takes place within or by agency of a community. 
Like any other method, this one has weaknesses. It requires practical decisions in terms of what to focus on in pedagogy or research, depending on the time available. This focus needs to be defined in terms of what aspects of analysis, theory or concept to explore. Of course, teachers and researchers will make practical decisions about what to apply and how often. The selective application and interpretation of Peirce's semiotics were not applied to undermine or simplify the scope or complexity of Peirce's work. It was applied to make it more accessible and applicable in higher education practice, not just within but beyond semiotic communities. This is a strength too. Another weakness concerns image accessibility and the slow progress of automated image screen readers for visually impaired and blind people. Although visually saturated social media such as Facebook and Instagram have introduced automated image alt text, more work needs to be invested in developing nuanced descriptive functions of a screen reader. The difficulty to do so only proves the complexity of human interpretation. Developing research into and platforms for a provision of an inquiry graphics semiotic naming of pictures' representamen and interpretant's denotation and connotation could help further development of image screen readers and artificial intelligence (AI).

\section{PSC Analysis Applications: Methodological Designs and a Related Metamodel}

A PSC inquiry method with photographs as inquiry graphics can be applied in both research and teaching practice in higher education. In both contexts, the PSC questions can be mixed with other visual methods such as photo elicitation (PE) or its sub-method photo-voice. A photo-voice inquiry could be realized by asking research participants or learners to provide their own choice of images, either found or taken to represent a concept/problem/theme that should be explored. Then, the researcher or teacher could devise questions that follow the PSC and IG analysis step (e.g. to name photographic elements, describe them, think of their sociocultural meanings and finally reflect on how all those elements individually and compositionally link to the inquiry concept(s), production and consumption). One possible way of exploring the life of photos is to try devising photo trails and understand how they are circulated - how and where they appear and reappear, for example, by using the reverse photo search provided by the Google Images search engine, as mentioned earlier in a few analytical questions. Clusters of pictures can be explored, for example, the ones that are labelled in a similar way or occur in clusters on the media, such as institutional websites or news media.

There would be some concept acting as a superimposed conceptual object over the image or images to focus the inquiry. By doing this superimposing of concept over image, the image-concept artefact or ensemble becomes a scientific-pictorial symbol, as the photograph gains a conventionally assigned meaning for the purpose of that specific inquiry. There are no adequate or right pictures for abstract concepts or media claims. All photographs and signs need to be first objects of inquiry, and not given objects of truth. This inquiry orientation challenges the assertion of truth claims, in education, just as much as in public discourse. In a teaching context, IG brings the materiality of the world into disciplinary conceptual domains, by prompting an understanding and exploration of the inherent link between the two (Deely 2007). By the sharing of meanings (between students and with teachers or by research participants), meaning making is externalized and becomes a central point in higher education practice, which supports both individual and collective knowledge development. 
When it comes to pedagogical method designs, many methodological variations can be devised and applied. This depends on the teacher as they will shape it for their own needs. For example, one such design is exemplified as an image-based concept inquiry (IBCI) cycle (Lacković 2010b). It includes these steps: (1) teacher and students first agree on the concept/theme/truth as the starting point for exploration; (2) students find or create a photograph to show an aspect (concrete materialization) of the concept; (3) students write a narrative about how the photograph links to the chosen concept; and (4) students share and discuss their images via a multiple-image display with the community, preferably first with peers and then with the teacher providing their take on the pictures and concept. All images and narratives are shared in an online learning space, for example, a VLE or any other repository such as a blog or digital portfolio. Inquiry graphics analysis can open an entirely new space of thinking and imagination, also revealing that inquiring images is neither common nor easy. In a teaching context, it forms a destabilizing liminal feeling and zone, which becomes a prerequisite for transformational experiences at the end of the learning cycle (Lackovic 2016).

Photographs, due to their representational quality that refers to the world's materiality presented on digital screens or in print, need to be finally accepted not only as objects of both visual and socio-material cultures but also as scholarly objects (Hallewell and Lackovic 2017). This is aligned with the growing field of sociomateriality in relation to education (Silva 2019; Fenwick, Edwards and Sawchuk 2015), which argues that materiality is interlinked with social or scientific meanings and inquiry. PSC method can provide tools for unpacking relations at the micro-macro level of meaning and practice intersection. This final section is closed by positioning the PSC method within such an intersectional model, a dynamic relationality map (or a metamodel). This map or metamodel is similar to Bronfenbrenner's (1979) ecological model to human development, expanded with non-human entities akin to De Sardan's (2005) notion of semiotic development. It can guide an exploration of photographs in postdigital education in relation to various theories and concepts that address the sociomaterial world (Fig. 4) and posthumanist research and pedagogy. The assemblages of pictures and concepts with its historicity, context, culture, emotions and social actors' prior knowledge are emergent, evolving and relational to the environment. I use the hyphenated term socio-material to signal my view of a possibility to analyse parts of an emerging whole yet embracing its emergent and holistic character. Peirce's synechism proposes the evolutionary and influential character of all signs, as signs-in-emergence through sign-action (Strand 2013). We can 'freeze' this emergence and pause accelerated hyper-visuality in education, not to worship it or deny its evolving character but to think, explore and unpack it.

Digital photographs and what individuals and groups do with them happen at the nexus of social, emotional, economic and technological practices and meanings (Lacković, 2019; Hurley 2019). Relations between organisms and environment are central to the existence in the world (Deely 2007) as complex and dynamic sign systems (Marais and Kull 2016; Maran 2006). This relational socio-material metamodel can be linked to various concepts and theories, in the so-called hard and natural sciences; in sociological, critical or posthumanist approaches; and in explorations of identity, politics, economy, ecology, technology, power and so on. The proposed metamodel is flexible to be embedded in theoretical or conceptual frames that researchers/students/teachers would choose. It signifies an (edu)semiotic turn beyond the 


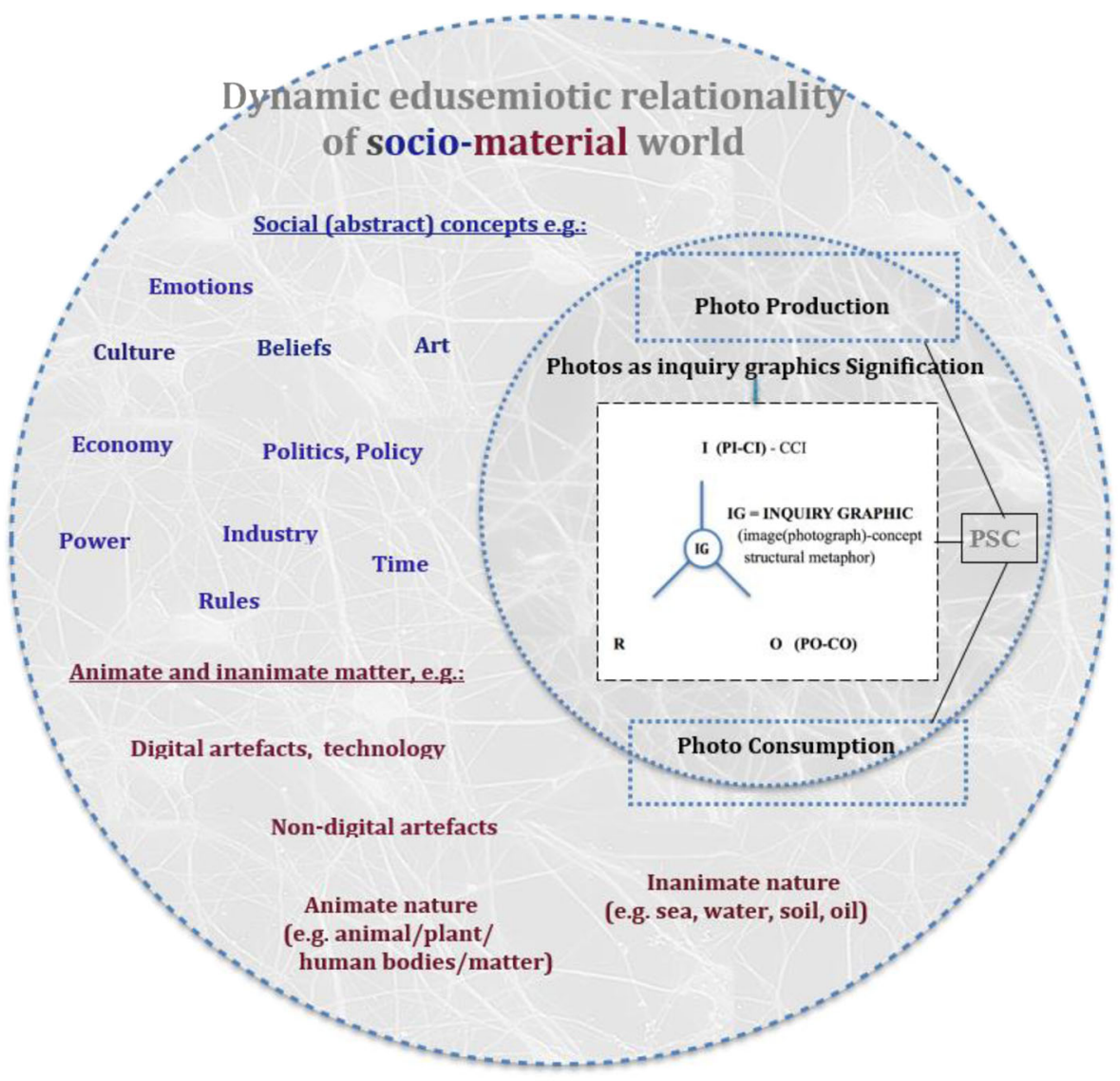

Fig. 4 Dynamic edusemiotic relationality map/model with the PSC and IG inquiry and relations embedded in the socio-material world; the discontinued lines applied in the figure for all spheres and the square imply the interconnectedness and relationality of all the presented entities, without strict boundaries

Anthropocene in education (Olteanu and Campbell 2018; Stables, Nöth, Olteanu, Pesce and Pikkarainen 2018), to explore socio-material ecosystems' relationality via the production, signification and consumption of postdigital signs.

\section{Conclusion}

This article introduced the production-signification-consumption (PSC) method and analysis, to contribute to knowledge in the fields of critical media literacy, teachinglearning and research in higher education. The PSC method is also an interdisciplinary, semiotic and postdigital response to non-analytical and uncritical engagement with digital images in the current post-truth era. It provides philosophical underpinnings rooted in Peirce's triadic sign and practical analytical questions that can be applied in curricula and research. The article explained how signs make meaning (to a human mind) and related this analytically to digital photographs. It reflected on the role of a sign's embodiment in the interpretation of concrete and abstract concepts in offline and 
online environments. The proposed semiotic analysis emphasizes the symbolic interrelatedness between perception, materiality, abstract concepts, thinking and knowledge. Ultimately, this article challenges the dichotomies of visual and intellectual, image and concept, body and mind, affect and logic in higher education and the world at large. Instead, it suggests that academic agents across the globe could teach and research complex and interrelated nuances of how signs make meaning to cultivate critical and postdigital semiotic awareness.

Open Access This article is licensed under a Creative Commons Attribution 4.0 International License, which permits use, sharing, adaptation, distribution and reproduction in any medium or format, as long as you give appropriate credit to the original author(s) and the source, provide a link to the Creative Commons licence, and indicate if changes were made. The images or other third party material in this article are included in the article's Creative Commons licence, unless indicated otherwise in a credit line to the material. If material is not included in the article's Creative Commons licence and your intended use is not permitted by statutory regulation or exceeds the permitted use, you will need to obtain permission directly from the copyright holder. To view a copy of this licence, visit http://creativecommons.org/licenses/by/4.0/.

\section{References}

Almeder, R. (1980). The philosophy of Charles Sanders Peirce: a critical introduction. Oxford: Basil Blackwell.

Arnheim, R. (1997). Visual thinking. Berkley and Los Angeles: University of California Press.

Bal, M., \& Bryson, N. (1991). Semiotics and art history. The Art Bulletin, 73(2), 174-208. https://doi. org/10.1080/00043079.1991.10786750.

Barthes, R. (2009/1972). Mythologies. Trans. Annette Lavers. London: Vintage Books.

Barthes, R. (1988). The semiotic challenge. Trans. Richard Howard. New York: Hill \& Wang.

Barthes, R. (1996). Connotation. In P. Cobley (Ed.), The communication theory reader (pp. 129-133). London: Routledge.

Benedict, G. A. (1985). What Are Representamens? Transactions of the Charles S. Peirce Society, 21(2), 241270. https://www.jstor.org/stable/40320088?seq=1 .

Berger, J., Blomberg, S., Fox, C., Dibb, M., \& Hollis, R. (1972). Ways of seeing. London: British Broadcasting Corporation \& Penguin.

Besley, T., Peters, M., \& Rider, S. (2018). Afterword: viral modernity. In M. Peters, S. Rider, M. Hyvönen, \& T. Besley (Eds.), Post-truth, fake news: viral modernity \& higher education (pp. 217-224). Singapore: Springer.

Bolter, J. D. (2001). Writing space: computers, hypertext, and the remediation of print. Mahwah: Lawrence Erlbaum Associates.

Bronfenbrenner, U. (1979). The ecology of human development. Cambridge, MA: Harvard University Press.

Bruner, J. S. (2009). Actual minds, possible worlds. Cambridge, MA: Harvard University Press.

Bulger, M., \& Davison, P. (2018). The promises, challenges and futures of media literacy. Journal of Media Literacy Education, 10(1), 1-21.

Deely, J. (2007). Intentionality and semiotics: a story of mutual fecundation. Scranton: University of Scranton Press.

De Sardan, J. P. O. (2005). Anthropology and development: understanding contemporary social change. London: Zed Books.

Debord, G. (1994). The society of the spectacle. Trans. Donald Nicholson Smith. New York: Zone Books.

Elleström, L. (2014). Material and mental representation: Peirce adapted to the study of media and arts. The American Journal of Semiotics, 30(1/2), 83-138. https://doi.org/10.5840/ajs2014301/24.

Evans, G.S. (2005) This could be a pipe: foucault, irrealism and Ceci n'est pas une pipe. The Cafe Irreal: international Imagination. http://cafeirreal.alicewhittenburg.com/review5.htm. Accessed 14 January 2020.

Fenwick, T., Edwards, R., \& Sawchuk, P. (2015). Emerging approaches to educational research: tracing the socio-material. London and New York: Routledge. 
Ford, D. R. (2018). Politics and pedagogy in the "post-truth" era: insurgent philosophy and praxis. London: Bloomsbury.

Freadman, A. (2001). The classifications of signs (II): 1903. Digital encyclopedia of C.S. Peirce. http://www. digitalpeirce.fee.unicamp.br/190fre.htm. Accessed 14 January 2020.

Gaines, E. (2010). Media literacy and semiotics. In E. Gaines (Ed.), Media Literacy and Semiotics (pp. 11-35). New York: Palgrave Macmillan.

Gaines, E. (2006). Media literacy and the future of semiotics: toward a semiotic taxonomy. Semiotics, 279286. https://doi.org/10.5840/cpsem20063.

Gourlay, L. (2010). Multimodality, visual methodologies and higher education. In M. Savin-Baden \& C. H. Major (Eds.), New approaches to qualitative research: wisdom and uncertainty (pp. 80-88). New York: Routledge.

Hallewell, M. J., \& Lacković, N. (2017). Do pictures 'tell' a thousand words in lectures? How lecturers vocalise photographs in their presentations. Higher Education Research and Development, 36(6), 11661180. https://www.tandfonline.com/doi/abs/10.1080/07294360.2017.1303454 .

Hayes, S. (2019). The labour of words in higher education: is it time to reoccupy policy? Leiden: Brill.

Hurley, Z. (2019). Imagined affordances of Instagram and the fantastical authenticity of female Gulf-Arab social media influencers. Social Media + Society, 5(1), 1-16. https://doi.org/10.1177/2056305118819241.

Jandrić, P. (2018). Post-truth and critical pedagogy of trust. In M. A. Peters, S. Rider, M. Hyvönen, \& T. Besley (Eds.), Post-truth, fake news: viral modernity \& higher education (pp. 101-111). Singapore: Springer.

Lacković, N. (2019). Graduate employability (GE) paradigm shift: towards greater socio-emotional and ecotechnological relationalities of graduates' futures. In M. Peters, P. Jandrić, \& A. Means (Eds.), Education and technological unemployment (pp. 193-212). Singapore: Springer.

Lacković, N. (2018). Analysing videos in educational research: an "Inquiry Graphics" approach for multimodal, Peircean semiotic coding of video data. Video Journal of Education and Pedagogy, 3(1), 123. https://doi.org/10.1186/s40990-018-0018-y.

Lacković, N. (2016). MultiMAP: exploring multimodal artefact pedagogy in digital higher education. In Proceedings of the 5th international conference on designs for learning: Aalborg Universitet København, Aalborg, Denmark (pp. 148-162). https:/eprints.lancs.ac.uk/id/eprint/85026/1/Proceedings_of_the_5th_ International_Conference_on_Designs_for_Learning.pdf. Accessed 14 January 2020.

Lacković, N., Crook, C., Cobb, S., Shalloe, S., \& D’Cruz, M. (2015). Imagining technology-enhanced learning with heritage artefacts: teacher-perceived potential of $2 \mathrm{D}$ and $3 \mathrm{D}$ heritage site visualisations. Educational Research, 57(3), 331-351. https://www.tandfonline.com/doi/full/10.1080 /00131881.2015.1058098.

Lacković, N. (2010a). Beyond the surface: image affordances in language textbooks that affect National Identity Formation (NIF). In M. Raesch (Ed.), Mapping minds (pp. 53-65). Oxford: Interdisciplinary Press.

Lacković, N. (2010b). Creating and reading images: towards a communication framework for higher education learning. Seminar.net, 6(1). https://journals.hioa.no/index.php/seminar/article/view/2462 .

MacKenzie, A., and Bhatt, I. (2020a). Lies, bullshit and fake news. Postdigital Science and Education, 2(1), 1-8. https://doi.org/10.1007/s42438-019-00085-4 .

MacKenzie, A., and Bhatt, I. (2020b). Opposing the power of lies, bullshit and fake news: the value of truth. Postdigital Science and Education, 2(1), 217-232. https://doi.org/10.1007/s42438-019-00087-2 .

Marais, K., \& Kull, K. (2016). Biosemiotics and translation studies. In Y. Gambier \& L. van Doorslaer (Eds.), Border crossings: translation studies and other disciplines (pp. 169-188). Anmsterdam: John Benjamins Publishing Company. https://doi.org/10.1075/btl.126.08mar .

Maran, T. (2006). Where do your borders lie? Reflections on the semiotical ethics of nature. In S. Gersdort \& S. Mayer (Eds.), Nature in literary and cultural studies: transatlantic conversations on ecocriticism (Vol. 3, pp. 455-476). Amsterdam/New York: Rodopi.

Merrell, F. (2005). Charles Sanders Peirce's concept of the sign. In P. Cobley (Ed.), The Routledge companion to semiotics and linguistics (pp. 28-39). London and New York: Routledge.

Mirzoeff, N. (2002). The visual culture reader. United Kingdom: Psychology Press.

Mitchell, W. T. (2005). What do pictures want?: The lives and loves of images. Chicago, IL: University of Chicago Press.

Mitchell, W. T. (2013). Iconology: image, text, ideology. Chicago, IL: University of Chicago Press.

Nöth, W. (2002). Can pictures lie. In W. Nöth (Ed.), Semiotics of the media: state of the art, projects, and perspectives (pp. 133-146). Berlin: De Gruyter Mouton. 
Nöth, W. (2011). From representation to thirdness and representamen to medium: evolution of Peircean key terms and topics. Transactions of the Charles S. Peirce Society: A Quarterly Journal in American Philosophy, 47(4), 445-481. https://doi.org/10.2979/trancharpeirsoc.47.4.445.

Olteanu, A., \& Campbell, C. (2018). A short introduction to edusemiotics. Chinese Semiotic Studies, 14(2), 245-260. https://doi.org/10.1515/css-2018-0015

Olteanu, A. (2019). Multiculturalism as multimodal communication. Berlin: Springer.

Panofsky, E. (2018). Studies in iconology: humanistic themes in the art of the Renaissance. New York: Routledge.

Parker, K. A. (1998). The continuity of Peirce's thought. Nashville, TN: Vanderbilt University Press.

Peters, M. A., Rider, S., Hyvönen, M., \& Besley, T. (Eds.). (2018). Post-truth, fake news: viral modernity \& higher education. Singapore: Springer.

Peters, M. A. (2017). Education in a post-truth world. Educational Philosophy and Theory, 49(6), 563-566. https://doi.org/10.1080/00131857.2016.1264114.

Peters, M. A., Besley, T., Jandrić, P., \& Bajić, M. (2016). Educational Research and Visual Cultures: the case of video publishing. Proceedings of AERA 2016.

Peirce, C. S. (1931-58). (quoted as CP). Collected papers, vols. 1-6, ed. C. Hartshorne and P. Weiss, vols. 78, ed. A. W. Burks. Cambridge, MA: Harvard University Press.

Rose, G. (2006). Visual methodologies: an introduction to interpreting visual materials (2nd ed.). UK: Sage Publications Ltd.

Santaella Braga, L. (2003). Why there is no crisis of representation according to Peirce. Semiotica, 143, 4552. https://doi.org/10.1515/semi.2003.013.

Silva, P. (2019). Sociomateriality and the agency of objects/things in education. In Conference proceedings EDUNOVATIC 2018: 3rd virtual international conference on education, innovation and ICT (p. 85). Eindhoven: Adaya Press.

Sless, D. (1981). Learning and visual communication. New York: Halsted Press.

Sontag, S. (1997). On photography. London: Penguin.

Stables, A., Nöth, W., Olteanu, A., Pesce, S., \& Pikkarainen, E. (2018). Semiotic theory of learning: new perspectives in the philosophy of education. London: Routledge.

Strand, T. (2013). Peirce's rhetorical turn: conceptualizing education as semiosis. Educational Philosophy and Theory, 45(7), 789-803. https://doi.org/10.1111/j.1469-5812.2011.00837.x.

Smith, M. (Ed.). (2008). Visual culture studies: interviews with key thinkers. Guildford, UK: Sage.

Tateo, L. (2018). Affective semiosis and affective logic. New Ideas in Psychology, 48, 1-11. https://doi. org/10.1016/j.newideapsych.2017.08.002.

The Cure (1989). Pictures of you [song]. In The Cure, Disintegration [musical album]. UK: Fiction Records. 